\title{
Preparação para a Aposentadoria como parte da Educação ao Longo da Vida
}

Retirement Preparation as Part of Lifelong Learning

Preparación para la Jubilación como parte de la Educación a lo Largo de la Vida
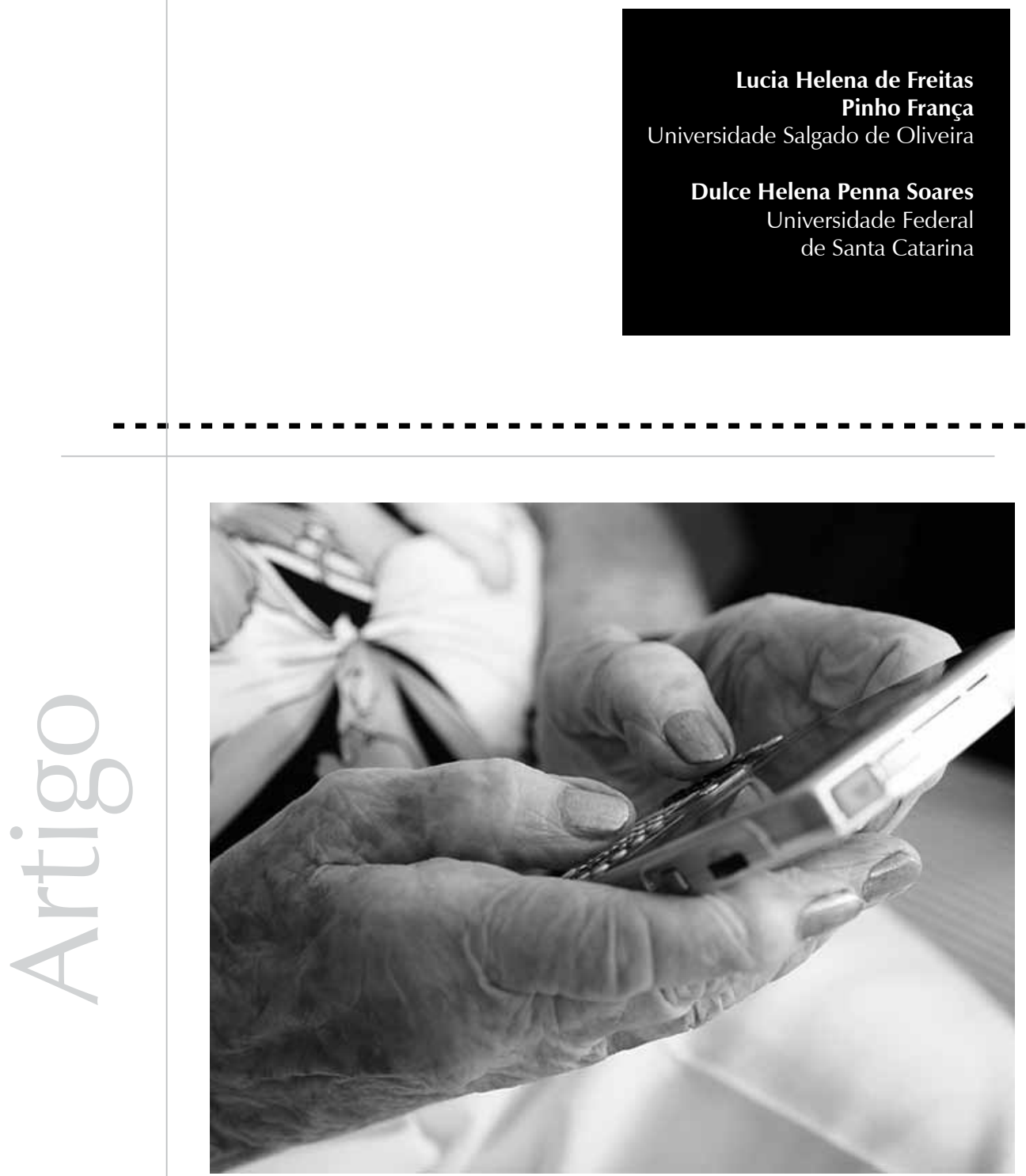
Resumo: O processo de globalização trouxe para as grandes organizações uma série de consequências, entre as quais a prática das aposentadorias incentivadas, em que diversos trabalhadores experientes foram dispensados, muitos sem qualquer preparação para uma vida que pode durar mais do que o tempo dedicado ao trabalho. Hoje muitas organizações já reconhecem o valor dos trabalhadores mais velhos, que, se atualizados, podem continuar tão motivados quanto já demonstraram em capacidade e experiência. Entretanto, alguns precisam ou desejam se aposentar, aproveitando o tempo livre para realizar atividades de desenvolvimento pessoal, de lazer, de cuidado com a saúde, desenvolvimento de projetos pessoais, relacionamentos sociais e familiares e mesmo para o engajamento em uma atividade profissional mais prazerosa. Este artigo pretende oferecer uma perspectiva do envelhecimento dos trabalhadores nas organizações e do desafio de lidar com a aposentadoria, analisando-se aspectos e variáveis que podem facilitar ou dificultar o bem-estar das pessoas nessa transição. Mais do que focar nas teorias que estariam fundamentando os Programas de Preparação para a Aposentadoria (PPAs), o artigo apresenta algumas pesquisas empíricas, de forma a incentivar a reflexão dos psicólogos sociais, organizacionais e orientadores profissionais sobre as suas possibilidades de inserção nessa área de atuação.

Palavras-chave: Programa de Preparação para Aposentadoria (PPA). Educação ao longo da vida. Transição de carreira. Projeto de vida.

Abstract: Globalization has brought a number of consequences to large organizations, amongst which are incentives such as pensions, and the laying off of a number of experienced employees, who were unprepared in most cases for a life that could last longer than the time they dedicated to their work. Today many organizations have begun to recognize the value of the older employees who, if brought up to date may not only remain motivated but also demonstrate their capacity and experience. However, some do need or want to retire, to spend most of their free time for personal development, leisure, health, personal projects, relationships with friends and family and even to engage in more enjoyable professional activities. The purpose of this article is to provide a perspective of the aging of employees within organizations and the challenges they face with retirement, assessing the aspects and variables that may facilitate or complicate the well being of these people through this transition. More than just focusing on theories based on Retirement Preparation Programs (RPP's), the article presents some empirical surveys to encourage reflection by social, organizational psychologists and professional counselors about the possibilities of their integration into this area.

Keywords: Retirement Preparation Programs (RPP's). Lifelong learning. Career transition. Lifetime project.

Resumen: El proceso de globalización trajo para las grandes organizaciones una serie de consecuencias, entre las cuales la práctica de las jubilaciones incentivadas, en que diversos trabajadores con experiencia fueron dispensados, muchos sin cualquier preparación para una vida que puede durar más de que el tiempo dedicado al trabajo. Hoy muchas organizaciones ya reconocen el valor de los trabajadores mayores, que, si son actualizados, pueden continuar tan motivados como ya demostraron en capacidad y experiencia. Mientras, algunos necesitan o desean jubilarse, aprovechando el tiempo libre para realizar actividades de desarrollo personal, de ocio, de cuidado con la salud, desarrollo de proyectos personales, relaciones sociales y familiares e incluso para el encaje en una actividad profesional más placentera. Este artículo pretende ofrecer una perspectiva del envejecimiento de los trabajadores en las organizaciones y del desafío de manejar la jubilación, analizándose aspectos y variables que pueden facilitar o dificultar el bienestar de las personas en esa transición. Más que enfocar en las teorías que estarían fundamentando los Programas de Preparación para la Jubilación (PPAs), el artículo presenta algunas pesquisas empíricas, de forma a incentivar la ponderación de los psicólogos sociales, organizacionales y orientadores profesionales sobre sus posibilidades de inserción en esa área de actuación.

Palabras clave: Programa de Preparación para Jubilación (PPA). Educación a lo largo de la vida. Transición de carrera. Proyecto de vida.

O aumento da expectativa de vida é um desafio mundial que atinge tanto os países desenvolvidos quanto aqueles em desenvolvimento, embora a maior diferença entre eles resida na esfera econômica, pelo fato de que antes de se tornarem velhos, os países desenvolvidos se tornaram ricos.
A preocupação, para os países como o Brasil, está em assegurar recursos suficientes para pagar pensões dignas e, ao mesmo tempo, garantir os serviços de saúde a uma população de idosos que aumenta vertiginosamente e cujos tratamentos têm custos maiores. 
A expectativa de vida dos brasileiros, atualmente, é de 73 anos, o que representa mais de 15 milhões de pessoas com 60 anos ou mais. Em 2050, a expectativa de vida alcançará 81 anos. Nessa época, o País terá igual número de idosos e de jovens, que representarão $18 \%$ da população geral, ou 47 milhões de pessoas em cada uma dessas faixas etárias. Por outro lado, as Nações Unidas (2002) indicam que a taxa de dependência dos aposentados da classe economicamente ativa tende a cair gradualmente ao longo dos próximos anos. O Brasil, em 2050, terá apenas três trabalhadores para sustentar um aposentado.

Todas essas projeções são preocupantes, pois os recursos não serão suficientes para garantir o bem-estar da população que está envelhecendo. Assim, uma série de medidas com a participação de todos os setores da sociedade precisa ser adotada.

No que diz respeito ao mundo do trabalho, uma das mais veementes recomendações da OMS (Organização Mundial de Saúde) e da ONU (Organização das Nações Unidas), adotadas no último encontro mundial sobre envelhecimento, em Madrid, foi a de garantir a mobilidade, a independência e a saúde dos trabalhadores e aposentados à medida que envelhecem. Essas recomendações (OMS, 2002) apontam políticas e ações a serem propostas pelas organizações, diante das necessidades de atualização dos trabalhadores mais velhos, da flexibilização de horários de trabalho, da redução dos preconceitos quanto à idade (ageismo ou idadismo) e harmonia nas equipes intergeracionais e da promoção dos programas de preparação para a aposentadoria para aqueles que desejam ou precisam sair do mercado de trabalho.

Por ser uma temática ainda nova, a aposentadoria é acompanhada de contradições, observadas tanto naqueles que estão na transição quanto nos vários segmentos da sociedade, e essa falta de preparo pode provocar uma série de conflitos. De um lado, estão aqueles que podem planejar se aposentar com maior tranqüilidade, podendo transformar essa fase em uma oportunidade de balanço, do despertar de novas possibilidades, seguidas por um recomeço ou otimização da vida; por outro lado, a aposentadoria hoje, e especialmente no Brasil (Camarano, 2001), não representa necessariamente a saída dos trabalhadores do mercado de trabalho, uma vez que muitos desejam continuar a ter uma atividade remunerada. Além disso, em 2020, espera-se que $11 \%$ da população economicamente ativa seja constituída por trabalhadores idosos, o que, segundo Camarano, é um contingente expressivo.

\section{Teorias relacionadas à aposentadoria}

Ao longo dos últimos 30 anos, um número efervescente de pesquisas empíricas e modelos teóricos proliferou na área da aposentadoria, principalmente nos países desenvolvidos, onde o contingente de idosos foi mais evidenciado. Para se entender melhor o trabalho de grande parte dos pesquisadores citados neste artigo, serão apresentadas, a seguir, as principais teorias subjacentes ao processo de decisão da aposentadoria.

Teoria dos papéis - focaliza os papéis que as pessoas ocupam na sociedade e a maneira pelas quais elas transitam entre esses papéis (Ashforth, 2001). Ao longo da vida, as pessoas podem assumir papéis diversificados (filho, marido, pai, trabalhador, voluntário, aposentado) identificados em diversos contextos, seja na família, seja na organização ou na sociedade. A transição dos papéis se dá quando ocorre uma mudança 
França e Vaughan (2008) ressaltam que a teoria da continuidade e a do curso de vida não são excludentes, mas complementares. Eles argumentam que a aposentadoria é uma transição que pode trazer perdas e ganhos, dependendo do contexto socioeconômico, político e cultural do país onde os aposentados vivem bem como das retrospectivas e perspectivas individuais e familiares na época do evento. entre dois papéis na mesma época (micro) ou em diferentes períodos na vida (macro). De acordo com Ashforth, a decisão de se aposentar pode ser vista como uma transição de papel macro, na qual o trabalhador se retira de um papel para entrar em outro.

Teoria da continuidade - de acordo com Atchley (1989), as pessoas tendem a manter por muito tempo padrões consistentes com as suas características psicológicas e seus ambientes físicos e sociais. A continuidade interna se refere às características psicológicas, tais como: autoconceito, idéias, atitudes, interesses, preferências e comportamentos. A continuidade externa estaria relacionada ao ambiente físico e social. A adaptação das pessoas às mudanças, quando confrontadas com desafios como o envelhecimento, ocorreria tanto através da continuidade interna quanto da externa. Atchley destaca que a aposentadoria é uma transição que se inicia antes do desligamento do trabalhador e continua até alguns anos depois do evento em si. Essa teoria rejeita a falta de função dos aposentados e enfatiza a importância de um trabalho em regime parcial voluntário ou pago (Kim \& Feldman, 2000) ou a sua substituição por outras atividades que tragam satisfação às pessoas.

Perspectiva do curso de vida - essa teoria é baseada no entendimento do comportamento da pessoa através da sua história de vida e do contexto no qual o evento está ocorrendo (Elder \& Johnson, 2003; Kim \& Moen, 2002; Quick \& Moen, 1998; Szinovacz, 2003). Tanto a história quanto o contexto podem criar caminhos para a transição, determinando os significados e estabelecendo as trajetórias através e além da transição. Um dos pesquisadores que aplicaram esse modelo para a aposentadoria reforçou os contextos dos indivíduos em nível micro e macro. O contexto micro inclui as variáveis personalógicas, como saúde, riqueza financeira, capital humano e família, e as características psicológicas, como personalidade, atitudes e padrões de comportamento. Já o contexto macro traduz as políticas governamentais, as condições do mercado de trabalho bem como as estruturas e as normas da população.

França e Vaughan (2008) ressaltam que a teoria da continuidade e a do curso de vida não são excludentes, mas complementares. Eles argumentam que a aposentadoria é uma transição que pode trazer perdas e ganhos, dependendo do contexto socioeconômico, político e cultural do país onde os aposentados vivem bem como das retrospectivas e perspectivas individuais e familiares na época do evento. Essa transição deve incorporar o projeto de vida, que, além de outros aspectos como o lazer e os relacionamentos, pode incluir um trabalho voluntário ou remunerado, em horário reduzido.

\section{A importância do trabalho e da educação ao longo da vida}

No final do século passado, testemunhamos o boom das aposentadorias incentivadas. Hoje os países reconhecem o valor da mão de obra mais velha, que pode ser tão atualizada, motivada e habilidosa quanto a capacidade e a experiência que já provaram possuir. Assim, a aposentadoria deve ser uma livre escolha, embora o planejamento seja fundamental para a adaptação nessa transição.

Para alguns trabalhadores, o trabalho está intimamente relacionado a sua identidade, e a aposentadoria não deve representar o fim do trabalho (Ashforth, 2001). Por outro lado, há trabalhadores que gostariam de mudar o estilo de vida, ajudando o próximo ou a sociedade, ou mesmo dedicar mais tempo aos amigos, à família, aos estudos ou ao lazer (Elder \& Johnson, 2003). Tanto para aquele 
que deseja continuar no mercado como para aquele que vislumbra a sua saída, é preciso haver uma atenção especial por parte da gestão de pessoas com aqueles trabalhadores obcecados pelo trabalho e com dificuldades para sequer imaginar o tempo livre que têm agora e terão no futuro.

No caso dos executivos, via de regra, a aposentadoria não exclui o trabalho, podendo estar incorporada a um novo começo que representa a oportunidade de experimentar um trabalho provisório, um trabalho de consultoria ou ingressar em atividades de voluntariado (França, 2004, 2008). Entretanto, recomenda-se que o trabalho pós-aposentadoria seja realizado em regime de meio-período, de forma que essas pessoas tenham oportunidade de equilibrar o seu tempo livre para lazer, voluntariado e outras atividades que lhes dêem prazer (Kim \& Feldman, 2000).

A demanda atual das organizações é oferecer um sistema que garanta o bem-estar dos trabalhadores mais velhos e dos que estão se aposentando, sem perder de vista o estímulo à motivação e à produtividade das equipes intergeracionais e a responsabilidade social com todos os seus trabalhadores, mesmo com aqueles que estejam deixando as organizações (França, 2008). O desafio está em identificar aqueles que desejam, precisam e têm condições de continuar no mesmo tipo de trabalho, que desejam um trabalho diferente ou mesmo que queiram se aposentar definitivamente, e apoiá-los nessa fase.

A chave para esse desafio está na educação ao longo da vida (lifelong learning) processo que prevê a educação tanto para a continuidade quanto para a saída do mercado de trabalho (França \& Stepansky, 2005). Como foi enfatizado por Holzmann (2002), a educação ao longo da vida, ou LLL, permite o acesso das pessoas à aprendizagem quando elas mais precisam, e não por terem atingido uma certa idade. É um processo que engloba o aprendizado formal (escolas, instituições de treinamento, universidades), o aprendizado não-formal (treinamento no trabalho) e o treinamento informal (família e comunidade), estendendo-se da infância à aposentadoria.

Na educação ao longo da vida, devem estar contidos os programas de atualização e desenvolvimento, o insumo de novas metodologias, a inserção digital para os trabalhadores mais velhos, a quebra dos preconceitos contra o envelhecimento, a integração entre os trabalhadores mais velhos e mais jovens e os PPAs. Conforme apontam França e Stepansky, o trinômio educaçãotrabalho-aposentadoria não precisa seguir essa ordem, e, para tanto, é fundamental a atualização dos trabalhadores mais velhos de forma a serem reinseridos no mercado, se assim o desejarem.

Para desenvolver essa empregabilidade, é fundamental uma mudança na legislação trabalhista, na flexibilização dos horários e na criação de novos contratos de trabalho (Stepansky \& França, 2008). Tais medidas permitem que os mais velhos exerçam a função de repassadores de conhecimento e, ao mesmo tempo, de receptores de tecnologia. Asssim, "esses resultados renderão às empresas o retorno da lucratividade e produtividade, ao mesmo tempo em que elas terão um trabalhador motivado, reforçado em sua autoestima e auto-imagem, com oportunidade da complementação da renda" (p. 54).

\section{Atitudes dos trabalhadores frente à aposentadoria}

A adaptação à aposentadoria depende de diversos fatores. Sob o ponto de vista psicossocial, é fundamental que sejam analisadas as atitudes dos trabalhadores diante das perdas e os ganhos que acompanham essa 
transição, de forma que os ganhos possam ser reforçados e o impacto das perdas sejam contornados através do planejamento. Para analisar as atitudes dos executivos de grandes organizações frente à aposentadoria, França (2004) construiu duas escalas, uma que mede a importância dos ganhos percebidos na aposentadoria (EPGR) e outra que mede a importância das perdas percebidas na aposentadoria (EPLR), que foram validados e cuja análise fatorial apresentou cinco dimensões de ganhos e quatro dimensões de perdas (França \& Vaughan, 2008).

As cinco dimensões dos ganhos na aposentadoria foram: i) liberdade do trabalho; ii) ter mais tempo para os relacionamentos. iii) novo começo; iv) ter mais tempo para atividades culturais e de lazer; v) ter mais tempo para os investimentos. As dimensões de perdas foram agrupadas em quatro grupos: i) aspectos emocionais do trabalho; ii) aspectos tangíveis do trabalho; iii) relacionamentos do trabalho; iv) salários e benefícios.

As atitudes frente à importância dos ganhos e das perdas da aposentadoria dependem de diversos aspectos que irão variar de acordo com a perspectiva individual, social, familiar, econômica, sociopolítica e ambiental da coletividade onde os aposentados estão inseridos. Os preditores individuais diziam respeito ao salário, ao percentual de perda esperada na aposentadoria, à saúde e à proximidade da aposentadoria. Os preditores sociais compreendiam quatro escalas elaboradas por França (2004): a influência da família e dos amigos na decisão da aposentadoria (FFIRD), a distribuição do tempo livre entre as atividades (de lazer e cultura, educação, trabalho na comunidade, espiritualidade, cuidado com a saúde, cuidado pessoal, rotinas domésticas, clubes, política e dedicação de tempo para os relacionamentos afetivos, sociais e familiares), o envolvimento e a satisfação que os trabalhadores mantêm com o trabalho (JPS) e as condições de vida da coletividade onde se insere o futuro aposentado (PCQL).

Os resultados da pesquisa de França (2008) com os executivos revelaram que os preditores sociais são mais eficazes do que os individuais ao prever as atitudes dos executivos, bem como influenciavam mais atitudes positivas do que negativas frente à aposentadoria. Dentre os preditores que mais influenciavam as atitudes positivas, estavam a alocação de tempo em atividades diversificadas e a influência da família e dos amigos na decisão da aposentadoria. Esse último resultado corroborou os de outros pesquisadores (Smith \& Moen, 1998; Szinovacz, DeViney, \& Davey, 2001). Assim, um programa de preparação para a aposentadoria deve reforçar o estímulo ao engajamento em atividades diversificadas e à harmonia no relacionamento familiar.

\section{Os Programas de Preparação para a Aposentadoria - PPA}

A transição da aposentadoria pode gerar ansiedade, principalmente pela falta de um planejamento que auxilie os trabalhadores a usufruir melhor o tempo nessa nova fase da vida (Bossé, Aldwin, Levenson, \& WorkmanDaniels, 1991). Para que a transição trabalhoaposentadoria seja efetivada de maneira mais tranqüila, é fundamental que sejam propostos programas de preparação para a aposentadoria nas organizações, enquanto planejamento para o futuro (França, 2002).

O PPA facilita o bem-estar dos futuros aposentados, pois enfatiza os aspectos positivos e oportuniza a reflexão sobre os aspectos negativos da transição bem como a discussão de alternativas para lidar com eles. É a oportunidade para receber informações e para a adoção de práticas e estilos de vida que promovam a saúde. É também o momento para (re)construir o projeto de vida a curto, médio e longo prazos, priorizando os seus interesses e as atitudes que precisa tomar para 
realizar seus projetos pessoais e familiares. O bem-estar dos aposentados representa, sem dúvida, um saldo positivo para toda a sociedade, pois afasta as possibilidades de doença e, por sua vez, acaba se revertendo em economia para os serviços de saúde, quer públicos, quer privados.

Em uma investigação realizada com 320 organizações brasileiras, apenas $18 \%$ adotavam o PPA, embora muitos dos seus principais executivos $(75 \%)$ tenham admitido que esses programas eram importantes para os trabalhadores (França, 2008). Mesmo nas organizações que adotam tais programas, poucos são os profissionais que realizaram algum curso sobre envelhecimento ou mesmo que tiveram oportunidade de realizar um diagnóstico sobre as percepções dos trabalhadores diante da aposentadoria e de seu respectivo planejamento. A organização, ao oferecer um programa que propicie bemestar aos seus empregados, acaba por agregar valor ao seu produto, sem falar no clima organizacional, em que trabalhadores jovens e mais velhos percebam a preocupação com o bem-estar dos empregados.

\section{Aspectos básicos a serem considerados em um programa}

O PPA deve conter um módulo informativo e um módulo experiencial ou "formativo" (França, 2002). O primeiro deverá oferecer palestras com profissionais que trabalham com a aposentadoria, entrevistas com aposentados bem sucedidos e empreendedores, "dicas" sobre bem-estar e saúde e apresentações sobre criatividade e hábitos saudáveis com psicólogos e médicos geriatras. O módulo informativo deve prever a presença de um familiar ou amigo convidado pelo aposentável para participar de algumas palestras e workshops.

Apesar da relevância do módulo informativo, ele deve ser complementado pelo módulo experiencial, que deverá aprofundar aspectos relacionados à qualidade de vida na aposentadoria, tais como: planejamento financeiro a médio e a longo prazo, dieta e nutrição, relacionamento familiar e social, atividades de lazer e educacionais e atividades remuneradas ou voluntárias. As vivências, dinâmicas de grupo e os workshops são metodologias privilegiadas nesse módulo.

O módulo informativo deve ter a duração aproximada de um ano. Assim que os aposentáveis optarem pela aposentadoria, é sugerido o seu ingresso no módulo formativo, com a duração sugerida também de um ano. Entretanto, alguns conteúdos contidos no planejamento para a aposentadoria que envolvem os fatores de risco devem ser iniciados assim que o trabalhador ingressa na organização e ao longo da sua carreira (França, 2002).

O acompanhamento do programa é também um ponto crucial para seu sucesso. A preparação para a aposentadoria não termina com a saída da empresa pelos trabalhadores, que devem ser acompanhados até cinco anos após sua saída. A avaliação deve ser periódica e prever continuidade após a aposentadoria. Para homens e mulheres, o trabalho parece ser o grande indicativo de bem-estar psicológico na aposentadoria, mas este deve ser analisado no contexto temporal do curso de vida para ambos. No caso dos homens, nos dois primeiros anos, a moral ainda está em alta, mas a ausência do trabalho nos anos subseqüentes ao período de lua-de-mel (nos dois primeiros anos) pode levar à depressão (Mann, 1991). Tudo indica que a rede de contatos sociais exerce grande influência na aposentadoria das mulheres, que, com mais compromissos sociais e contatos, apresentam maior satisfação na aposentadoria (Reeves \& Darville, 1994). 


\section{A importância do projeto de vida no PPA}

Se a aposentadoria é de livre escolha, o projeto de vida pós-aposentadoria é a oportunidade que o trabalhador tem para experimentar novas situações, desenvolver habilidades, aptidões e mesmo descobrir novos interesses. O projeto oferece a possibilidade de inserir contextos tão importantes quanto o trabalho, como a saúde, os relacionamentos, os investimentos, as atividades intelectuais, domésticas, culturais e o lazer. Na aposentadoria, o trabalho, como uma atividade laborativa, formal ou não formal, remunerada ou voluntária, deverá ocupar um espaço compartimentado e realizado em período reduzido (Quick \& Moen, 1998).

Há uma carência de estudos sobre o conceito de projeto de vida no Brasil, em especial com a população de aposentados. A elaboração de projetos é uma característica essencialmente humana, que inclui não somente a intenção de realizar algo para o futuro mas também a de viver a própria vida como um projeto. O projeto implica uma dimensão temporal - o futuro, sob forma de antecipação, e a noção de abertura, como algo ainda não determinado, um porvir. O projeto de futuro está em constante transformação, simbolizando assim sua contínua construção e reconstrução (Soares \& Sestren, 2007).

Segundo Boutinet (1990), ao mesmo tempo em que o projeto é o momento que integra em seu interior a subjetividade e a objetividade, é também o momento que funde, em um mesmo todo, o futuro previsto e o passado recordado. Através do projeto, constrói-se um futuro desejado, esperado. O projeto não pode ser para um futuro longínquo nem também se limitar a ser muito imediato. Seu caráter parcialmente determinado faz com que ele não seja totalmente realizado, sempre passível de modificações. Isso significa que todo projeto, através da identificação de um futuro desejado e dos meios próprios para torná-lo realidade, se dá num certo horizonte temporal, no interior do qual ele evolui. Mas o projeto não termina no ambiente onde sua evolução é previsível. Ele diz respeito, primeiramente, ao autor, e se dá uma perspectiva de um futuro que é almejado. Boutinet define então projeto como a antecipação operatória, individual ou grupal, de um futuro desejado.

Boutinet descreveu três etapas características, marcada pela elaboração de projetos, na França: o projeto adolescente de formação profissional e inserção no mercado, o projeto vocacional de adulto e o projeto de aposentadoria. Perguntamos-nos como ficam os projetos dos aposentados, ao repensarem sua trajetória profissional e reviverem as questões relativas aos projetos idealizados ainda quando jovens, se estes foram ou não realizados em toda uma vida de trabalho. E quais os projetos que ficaram para trás, e não puderam ser realizados? Será que esses sujeitos que agora deixam o mundo do trabalho puderam realizar os seus próprios projetos profissionais ou trabalharam no que foi possível, no emprego que conseguiram? Nessa perspectiva, o projeto de vida na aposentadoria poderá contemplar também o re-ingresso no mercado de trabalho.

Um exemplo de avaliação e reconstrução de projeto de vida que pode ser utilizado nos programas de preparação para a aposentadoria é a autobiografia orientada, proposta pelo gerontólogo James Birren (Birren \& Deutchman, 1991), que incentiva a auto-estima e a habilidade para controlar a própria vida. A autobiografia orientada é um tipo de avaliação do que as pessoas viveram, no sentido de projetar o que querem realizar para o futuro. A autobiografia foi formulada 
para combinar as experiências individuais e de grupo com as histórias de vida, utilizando revisões semi-estruturadas da vida através de redações realizadas pelos participantes em torno de temas. Esses temas partem de pontos ramificadores da vida das pessoas, como, por exemplo, o trabalho, o papel do dinheiro, a saúde e a imagem do corpo, amor e ódio, identidade sexual, família, experiências com a morte e outras perdas, aspirações, metas, valores e influências que sejam significativas para as pessoas.

O facilitador do PPA deve procurar contribuir com a reflexão sobre o projeto de vida pessoal e profissional e, a partir de tal reflexão, buscar novos caminhos, auxiliando as pessoas a se darem conta de como lidam consigo mesmo, com as relações de trabalho e sociais, para então, se necessário, reestruturar tais relações de um modo adequado para si mesmo e para a sociedade. Os trabalhadores deverão discutir as dificuldades encontradas em face das metas estabelecidas por eles, os motivos da procrastinação, as estratégias e as alternativas que utilizaram e devem utilizar para dirigirem sua vida de acordo com o que desejam. Como enfatizado por França (1999), mais do que dispor da liberdade de escolha, aquele que está em vias de se aposentar deve obter elementos necessários para gerenciar o seu projeto de vida, administrando as perdas e reforçando os ganhos, em função dos desejos e possibilidades.

Oscandidatos à aposentadoria podem e devem continuar no mercado de trabalho, desde que tenham saúde, desejo e invistam na sua atualização. A transição para a aposentadoria pode representar uma oportunidade para a mudança profissional, para a busca por um trabalho mais prazeroso ou condizente com um novo perfil profissional. Esse trabalho pós-aposentadoria deve ser, prioritariamente, executado em horário reduzido para que esses trabalhadores possam dispor de tempo livre para o lazer, para os relacionamentos familiares e para outros projetos não ligados à vida profissional.

\section{A reorientação como redefinição das possibilidades profissionais na aposentadoria}

A Orientação Profissional (OP) é o trabalho que tem por objetivo auxiliar jovens e adultos a escolherem uma profissão. Pode-se trabalhar a primeira escolha, geralmente em grupo de jovens vestibulandos e universitários, como também a reorientação, ou seja, uma nova escolha profissional.

O trabalho de reorientação se assemelha ao de OP, pois vai buscar, com a pessoa, identificar uma nova profissão auxiliando ou reorientando a compreensão de suas escolhas anteriores e visualizando os motivos pelos quais se decidiu pelas preferências feitas, além de localizar onde reside sua insatisfação com a primeira escolha. Para Garcia (2006), a reorientação profissional pode trabalhar no resgate dos projetos profissionais que ficaram adormecidos naquele trabalhador que se iniciou em uma profissão sem ter necessariamente se questionado ou por ter se importado apenas em viver aquele momento, ou ainda que considerou apenas o futuro, sem levar em conta todo o processo decisório pelo qual estava passando.

A reorientação profissional pode ser realizada em diferentes situações da vida da pessoa, dependendo do momento no qual esta se encontra e da sua necessidade e vontade de mudar. Pode ser realizada com jovens universitários insatisfeitos com suas escolhas, ou ainda em crise no meio do curso, como também com profissionais que se encontram no meio da carreira, satisfeitos ou não com suas atividades ou com desempregados, muitas vezes por falta de uma nova opção profissional, e ainda com os aposentados. 
Soares, Krawulski, Siqueira, Caetano e Cascaes (2000), ao comentarem sobre o trabalho de reorientação realizado, afirmam que os aposentados podem ser incluídos. Muitas vezes procuram uma nova colocação, seja pela necessidade de complementar os ganhos, pois os seus vencimentos são insuficientes, seja porque querem nova ocupação como modo de preencher o tempo vago ou até para concretizar um antigo sonho ainda não realizado.

Nos programas de preparação para a aposentadoria, é fundamental discutir a questão das escolhas profissionais realizadas ao longo da vida, pois estas aparecem como pano de fundo para se compreender como o sujeito se relaciona com suas possibilidades de futuro, e é também fundamental discutir sobre como se constitui a identidade do aposentado, a partir do momento no qual não tem mais como sobrenome o "nome da instituição" onde ele trabalhava, e o modo como os aposentados e os pré-aposentados dão significado a seus projetos futuros.

Soares, Costa, Rosa e Oliveira (2007), ao relatarem experiências com grupos de aposentados, afirmam que, entre as indagações do aposentar-se, uma certeza se impõe: a aposentadoria transforma completamente a vida da pessoa. Muitas vezes altera rotinas e hábitos, expectativas e relacionamentos, sendo fundamental uma preparação para o enfrentamento dessas mudanças e a reflexão sobre o planejamento pessoal para o futuro.

A aposentadoria tem chegado para pessoas ainda jovens, que estão em condições de continuar trabalhando e de buscar outras atividades profissionais. Para Soares (2002), a reorientação pode ajudar a buscar os sonhos adormecidos, a realização de projetos deixados para trás por motivos familiares e profissionais.
Santos (1990) estudou a relação da identidade pessoal e a aposentadoria, e encontrou duas maneiras de encarar a aposentadoria: a primeira é enquanto crise (através da recusa em aceitar essa situação ou da volta ao trabalho por sobrevivência), e a outra enquanto liberdade (através da assistência aos familiares ou da busca do prazer através do lazer). Dessas duas modalidades, os primeiros continuam trabalhando, geralmente na mesma atividade profissional, ou podem procurar outra ocupação, no sentido de buscarem melhor forma de sobrevivência, uma vez que os vencimentos de aposentados não lhes permitem se sustentar. Eles têm dificuldade em aceitar a aposentadoria e, por isso, continuam trabalhando; sendo assim, estes seriam os que mais necessitariam de um apoio, mas a recusa em aceitar a aposentadoria os impede de procurar ajuda.

Os indivíduos da segunda categoria se sentem livres, fazem projetos de futuro, geralmente ligados à expansão, e muitas vezes voltam a estudar. É um momento especial em suas vidas, em que muitas vezes buscam "realizar" o que sempre sonharam, mas que, por diferentes motivos, não puderam fazer anteriormente.

Para Soares et al. (2000), o papel do orientador deve ser o de contribuir com a reflexão sobre o projeto de vida pessoal e profissional, e, a partir de tal reflexão, auxiliar as pessoas a se darem conta de como lidam consigo mesmas e com as relações de trabalho e sociais, para então, se necessário, reestruturar tais relações, de um modo adequado para si mesmo e para a sociedade. É fundamental que, nesse processo, os indivíduos construam "pontes" entre o mundo interno e externo e aprendam a lidar com as possibilidades e as limitações presentes em ambos.

A aposentadoria oportuniza encontrar uma nova ocupação relacionada com algum antigo projeto de futuro, ligado às 
expectativas familiares. O projeto não é totalmente realizado, e está sempre passível de modificações.

A fim de identificar os projetos de futuro para a aposentadoria, é importante refletir acerca da centralidade do trabalho para as pessoas, sobre seus aspectos psicológicos e sociais, sobre as dificuldades enfrentadas na ruptura com diversas identificações devido à aposentadoria e quanto à elaboração de novos projetos de futuro. O diagnóstico deve identificar quais os conteúdos a serem oferecidos em um programa de preparação para a aposentadoria, permitindo ainda desvendar o nível de motivação e de envolvimento dos trabalhadores mais velhos com a organização.

É sabido que existe uma relação direta da motivação e do envolvimento com as oportunidades de desenvolvimento profissional. Existe uma sequência "trabalho-aposentadoria-trabalho", que pode ser um círculo, e não precisa seguir necessariamente essa ordem, ou seja, é possível que trabalhadores mais velhos produzam tanto ou melhor, se atualizados e estimulados pela organização. Da mesma forma, aposentados podem continuar a produzir, se houver interesse de sua parte e da parte da organização, sob outro tipo de contrato, em regime de meio expediente ou consultoria.

Em pesquisa realizada no LIOP - Laboratório de Informação e Orientação Profissional da UFSC, por Costa e Soares (2008), com aposentados e pré-aposentados, na qual foi solicitado que falassem sobre seus projetos de vida futura, foram identificadas seis grandes categorias de projetos: projetos de desenvolvimento pessoal, projetos relacionados ao lazer, projetos relacionados à saúde, projetos financeiros, projetos relacionados a atividades prazerosas diversas e projetos relativos à superação pessoal.
Os projetos de lazer e aqueles ligados a atividades prazerosas estão entre os mais presentes em nossos pesquisados. Dentre os projetos relacionados a atividades prazerosas, constam: a realização de sonhos do passado, a busca por maior convívio familiar (resgatar afetos), fazer algo pelo mundo (cuidar do meio ambiente, voluntariado, ajudar pessoas) e novas atividades que proporcionem prazer. Dentre os projetos ligados ao lazer, figuram: realizar viagens, atividades artísticas, como aprender a tocar um instrumento musical, pintura, desenho, promover encontros sociais (cozinhar para os amigos), praticar esportes por lazer (e não por indicação médica) e hobbies em geral.

Reorientar projetos de futuro na aposentadoria é, como explica Soares (2002), auxiliar a romper o vínculo com a antiga profissão para poder ir em busca da verdadeira escolha de uma atividade que responda às necessidades da pessoa e também para facilitar ao indivíduo a compreensão de seu progresso em suas sucessivas "escolhas", auxiliando-o a ver a relação existente entre as diversas decisões que vai tomando ao longo da vida profissional, a fim de projetar um futuro com qualidade de vida e realizações. A situação mais feliz é aquela em que o trabalho e o hobby coincidem, ou seja, o trabalho representa, ao mesmo tempo, uma fonte de prazer (Soares 1997).

\section{Considerações finais}

O envelhecimento populacional trouxe uma série de conseqüências e desafios para os governos. Grande parte desses desafios está relacionada ao alto custo das aposentadorias, a uma renda de aposentadoria digna para o futuro aposentado, à manutenção do plano de assistência médica e, ao mesmo tempo, à liberdade para os trabalhadores decidirem se devem se aposentar ou continuar trabalhando.

A aposentadoria se apresenta como um período de incertezas, apesar das sofisticadas 
projeções econômicas e atuárias tão em voga no mundo de hoje. Há, sem dúvida, uma carência de estudos e pesquisas diante dessa realidade, e são desconhecidos e imprevisíveis os comportamentos dos trabalhadores e das empresas frente ao aumento da expectativa de vida.

A aposentadoria coincide com a maturidade psicológica. Nos últimos anos, percebese uma mudança gradativa de atitude com relação aos trabalhadores idosos, muitas vezes denominados "maduros". Empregadores podem descobrir algumas vantagens na contratação de trabalhadores com mais de 50 anos em comparação com os jovens. Entre essas vantagens, podemos citar o fato de que eles se sentem mais motivados e criativos nas atividades que lhes são propostas, têm mais comprometimento e autonomia, são mais confiáveis e apresentam maior capacidade na solução de problemas. Eles também apresentam mais coerência e ética em seus comportamentos no trabalho, e possuem, geralmente, maior estabilidade emocional e, acima de tudo, experiência.

Entretanto, é preciso que mais empresas contemplem, em suas políticas de recursos humanos, programas de preparação para a aposentadoria, como estabelecido na Lei no 8.842 (Brasil, 1994), que trata da competência dos órgãos públicos em "criar e estimular a manutenção de programas de preparação para aposentadoria nos setores público e privado com antecedência mínima de dois anos antes do afastamento" (p. 78). Também não são conhecidas iniciativas por parte das organizações para lidar com o ageismo ou o idadismo, os preconceitos frente ao desempenho e o aproveitamento dos trabalhadores mais velhos.

A cada dia se faz mais presente a importância de um programa de educação apoiado pelas empresas e pelo governo, voltado tanto para a retenção do trabalhador mais velho no mercado quanto para o apoio a sua aposentadoria, conforme o caso. Todos os trabalhadores, jovens e idosos, devem ter oportunidades de emprego e condições para assegurar um futuro digno para si mesmos. O ponto de partida para que os governos lidem com esses desafios é oferecer condições para os trabalhadores planejarem o seu futuro e se manterem atualizados, motivados, independentes e socialmente participantes. Para que essas condições sejam cumpridas, é importante que o governo, com o apoio da mídia, das empresas e dos próprios trabalhadores, possa assumir a sua responsabilidade coletiva. A organização, em especial, deve ser sensibilizada frente aos benefícios que ela alcançará através da integração de suas equipes intergeracionais.

A preparação para a aposentadoria é um recurso a ser disponibilizado pelas organizações, desde que garantida a oportunidade da livre escolha. Nesse programa, os futuros aposentados são estimulados a realizar atividades intelectuais, a repensar nas novas opções de vida profissional, mais gratificantes e com horários reduzidos, a questionar as oportunidades de lazer e a forma de obter o melhor de seus relacionamentos afetivos, familiares e sociais. Esses conteúdos devem ser inseridos no projeto de vida, e os próprios aposentáveis estabelecerão as prioridades, de acordo com os seus interesses.

Além disso, essa preparação deverá estar pautada na construção de um projeto de vida em uma nova fase, auxiliando a pessoa a se apropriar de seus desejos, motivações e reais possibilidades na busca de ser feliz. Pela maturidade já alcançada, esse projeto, indubitavelmente, inclui o envolvimento e o compromisso com ações construtivas para a sociedade. 
Lucia Helena de Freitas Pinho França*

Doutora em Psicologia Social pela Universidade de Auckland, Nova Zelândia, professora do Programa de PósGraduação em Psicologia da Universidade Salgado de Oliveira - UNIVERSO, Niterói, RJ - Brasil.

\section{Dulce Helena Penna Soares}

Doutora em Psicologia Clínica pela Universidade de Strasbourg, França, professora do Programa de PósGraduação em Psicologia da UFSC - Universidade Federal de Santa Catarina, Florianópolis, SC - Brasil.

\section{*Endereço para envio de correspondência:}

Rua Prof. - Estelita Lins, 99 ap. 306 - Laranjeiras, Rio de Janeiro, RJ - Brasil - CEP: 22245-150

E-mail: luciafranca@luciafranca.com

Recebido 24/11/2008, Reformulado 08/06/2009, Aprovado 13/06/2009 
Referências
Ashforth, B. (2001). Role transitions in organizational life: An identity based perspective. Mahwah, NJ: Erlbaum.

Atchley, R. C. (1989). A continuity theory of normal aging. The Gerontologist, 29, 183-190.

Birren, J. E., \& Deutchman, E. D. (1991). Guiding autobiography groups for older adults: Exploring the fabric of life. Baltimore: The Johns Hopkins University Press.

Bossé, R., Aldwin, C. M., Levenson, M. R., \& WorkmanDaniels, K. (1991). How stressful is retirement? Findings form the Normative Aging Study. Journal of Gerontology: Psychological Sciences, 46(1), 9-14.

Boutinet, J. P. (1990). Anthropologie du projet (301 pp.). Paris: PUF.

Brasil. (1994, 4 de janeiro). Lei no 8.842. Dispõe sobre a Política Nacional do Idoso, cria o Conselho Nacional do Idoso e dá outras providências. Diário Oficial da República Federativa do Brasil, Brasília, DF, 132(3), 77-79.

Camarano, A. A. (2001). O idoso brasileiro no mercado de trabalho [Trabalho completo]. In $5^{\circ}$ Congreso Nacional de Estudios del Trabajo, 1 a 3 de agosto de 2001, ASET, Buenos Aires.

Costa, A. B., \& Soares, D. H. P. (2008). Projetos de futuro na aposentadoria: uma discussão fundamentada pela orientação profissional em psicologia. In Perspectivas en psicología (pp. 37-46). Mar del Plata, Argentina: Facultad de Psicología de la UNMdP.

Elder, G. H., \& Johnson, M. K. (2003). The life course and aging: Challenges, lessons, and new directions. In R. A. Sttersten, Jr. (Ed.), Invitation to the life course: Toward new understandings of later life (pp. 49-81). Amityville, NY: Baywood.

França, L. H. (1999). Preparação para aposentadoria: desafios a enfrentar. In R. P. Veras (Org.), Terceira idade: alternativas para uma sociedade em transição (pp. 11-34). Rio de Janeiro: Relume-Dumará/Unati/UERJ.

França, L. H. (2002). Repensando a aposentadoria com qualidade - um manual para facilitadores em programas de educação para a aposentadoria [Livro eletrônico]. Rio de Janeiro: Universidade Aberta da Terceira Idade/UnATI/UERJ. Recuperado em 20 de novembro de 2008, de http://www.crde-unati.uerj. $\mathrm{br} /$ publicacoes/pubEletronica.asp

França, L. H. (2004). Attitudes towards retirement: A cross-cultural study between New Zealand and Brazilian executives. Ph.D Thesis, Departament of Psychology, The University of Auckland, New Zealand.

França, L. H. (2008). O desafio da aposentadoria. Rio de Janeiro: Rocco.

França, L. H., \& Stepansky, D. W. (2005). Educação permanente para trabalhadores idosos - o retorno à rede social. . Boletim Técnico do SENAC, 31(2), 47-55.

França, L. H., \& Vaughan, G. (2008). Ganhos e perdas na aposentadoria: percepção dos executivos brasileiros e neozelandeses. Psicologia em Estudo, 13(2), 207-216.

Garcia, M. (2006). Reorientação profissional em grupo planejamento por encontros. In M. D. Lisboa \& D. H. P. Soares (Orgs.), A orientação profissional em ação: formação e prática de orientadores profissionais (2a ed., pp. 144-168). São Paulo: Summus.

Holzmann, R. (2002). Population aging and old-age income: The need for re-design and life-long learning [Powerpoint presentation]. The $6^{\text {th }}$ Global Confer- ence, Maturity Matters, International Federation on Ageing, 27-30 ${ }^{\text {th }}$ October, 2002, Perth, Australia.

Kim, S., \& Feldman, D. (2000). Working in retirement: The antecedents of bridge employment and its consequences for quality of life in retirement. Academy of Management Journal, 43(6), 1195-1210.

Kim, S., \& Moen, P. (2002). Retirement transitions, gender, and pyshcological well-being: A life-course model. Journals of Gerontology. Series B: Personnel Psychology, 51, 623-642.

Mann, J. (1991). Retirement: What's happen to husband wife relationships? Journal of Geriatric Psychiatry, 24(1), 41-46.

Quick, H. E., \& Moen, P. (1998). Gender, employment, and retirement quality: A life course approach to the differential experiences of men and women. Journal of Occupational Health Psychology, 3(1), 44-64.

Reeves, J. B., \& Darville, R. L. (1994). Social contact patterns and satisfaction with retirement of women in dual-career/earner families. International Journal of Aging \& Human Development, 39(2), 163-175.

Santos, M. F. (1990). Identidade e aposentadoria. São Paulo: E.P.U.

Smith, D. B., \& Moen, P. (1998). Spousal influence on retirement: His, her, and their perceptions. Journal of Marriage \& the Family, 60(3), 734-744.

Soares, D. H. P. (1997). Choix professionnel - Projet des parents - Projet des adolescents. Villeneuve d'Ascq Cedex, France: Presses Universitaires du Septentrion.

Soares, D. H. P. (2002). A escolha profissional: do jovem ao adulto. São Paulo: Summus.

Soares, D. H. P., Costa, A., Rosa, A. M., \& Oliveira, M. L. (2007). Aposenta-ação: programa de preparação para a aposentadoria. Estudos Interdisciplinares sobre o Envelhecimento, 13, 123-134.

Soares, D. H. P., Krawulski, E., Siqueira, M. B., Caetano, S. S., \& Cascaes, C. T. (2000). Reorientação profissional, orientação e o processo de escolha: notas sobre experiências vividas. Revista de Ciências Humanas, 28, 81-100.

Soares, D. H. P., \& Sestren, G. (2007). Projeto profissional: o redimensionamento da carreira em tempos de privatização. Psicologia \& Sociedade, 19, 66-74.

Szinovacz, M. (2003). Context and pathways: Retirement as institution, process and experience. In G. A. Adams \& T. A. Beehr (Eds.), Retirement: Reasons, processes, and results (pp. 6-52). New York: Springer.

Szinovacz, M., DeViney, S., \& Davey, A. (2001). Influences of family obligations and relationships on retirement: Variations by gender, race, and marital status. Journal of Gerontology: Social Sciences; 56B(1), S20-S27.

Stepansky, D. W., \& França, L. H. (2008). O equilíbrio entre o trabalho e vida pessoal como preditor de bem-estar dos trabalhadores. Boletim Técnico do Senac, 34(1), 65-71.

United Nations. (2002). Population ageing-2002 [Graph]. Population Division, Department of Economic and Social Affairs. New York: Author.

World Health Organization. (2002). Active ageing: A policy framework (Envelhecimento ativo: uma política de saúde). Recuperado em 20 de fevereiro de 2005, de http://www.who.int/ageing/publications/active/en 